\title{
EL PUEBLO GITANO VASCO EN EL SIGLO XIX, ENTRE LA ASIMILACIÓN Y LA REAFIRMACIÓN
}

\section{The Basque Gypsy people in the nineteenth century: Between assimilation and reaffirmation}

\author{
DAVID MARTÍN SÁNCHEZ \\ Grupo de investigación interdisciplinar PENDARIPÉN \\ davnouse@hotmail.com
}

Cómo citar/Citation

Martín Sánchez, D. (2018).

El pueblo gitano vasco en el siglo xix,

entre la asimilación y la reafirmación.

Historia y Política, 40, 53-81

doi: htpp://doi.org/10.18042/hp.40.03

(Recepción: 11/09/2017. Evaluación: 02/01/2018. Aceptación: 01/06/2018. Publicación: 02/11/2018)

\section{Resumen}

Este artículo se propone analizar la particular evolución de una serie de familias gitanas en el ámbito geográfico y cultural vasco durante el siglo XIX. Las investigaciones han tendido a homogeneizar el pasado del pueblo gitano, a pesar de que ciertos factores diferencien su dinámica evolutiva. Para lograr este objetivo se ha recurrido a una interpretación que acepta las prerrogativas legisladoras de las provincias vascas, la doble imposición penal, así como su singular cultura, como condicionantes de su progreso desigual. En un intento por superar esta visión uniforme de la historia del pueblo gitano, se ha recurrido al análisis microhistórico para conocer mejor el pasado de las familias gitanas vascas. Las conclusiones han llevado a establecer la génesis de un grupo humano, el de los gitanos vascos: represión y posteriormente asimilación. Empero, el contacto con otros grupos de gitanos castellanos, quienes, paradójicamente, los verán como a payos, ayudó a que las familias gitanas vascas en España no se diluyeran completamente. 


\title{
Palabras clave
}

Pueblo gitano; siglo xIx; País Vasco; represión; asimilación.

\begin{abstract}
Research has tended to treat the Gypsy people's past as if it were homogenous, in spite of certain factors that characterize their evolutionary dynamics as different. The objective of this article was to analyse the individual evolution of a series of Gypsy families in the cultural and geographical environment of the Basque Country in the nineteenth century. The factors that determined their uneven progress can be summed up as the possibility of double jeopardy due to the imposition of the legislative prerogatives of the Basque provinces at the same time as the law of Spain, and their unique culture. Micro-historical analysis was used in an effort to move beyond the uniform view of the history of the Gypsy people and to find out more about Basque Gypsy families. The conclusions led to the establishing of a previously undefined human group, the Basque Gypsies, born of repression, followed by assimilation. It was contact with other groups of Castilian Gypsies-who paradoxically regarded them as Gazhe [non-Gypsies] - that helped prevent Basque gypsy families in Spain from becoming completely diluted in cultural terms.
\end{abstract}

\section{Keywords}

Gypsy people; nineteenth century; Basque Country; repression; assimilation. 


\section{SUMARIO}

I. INTRODUCCIÓN. II. PRIMERAS ETAPAS DE UNA HISTORIA: LA LLEGADA DEL PUEBLO GITANO A TIERRAS VASCAS. III. LAS ACTITUDES DE LA SOCIEDAD VASCA ANTE LOS GITANOS DURANTE EL SIGLO XIX. IV. LAS MEDIDAS REPRESIVAS EN EL TRÁNSITO DEL ANTIGUO AL NUEVO RÉGIMEN. V. MISMAS FAMILIAS, DISTINTOS CAMINOS. VI. CONCLUSIONES. BIBLIOGRAFÍA.

\section{INTRODUCCIÓN}

El objeto protagonista de este estudio es el gitano, entendido como el sujeto, hombre y mujer, antepasado de los individuos que hoy se reconocen como pertenecientes a dicho pueblo, durante un periodo de tiempo y un ámbito geográfico determinados. En nuestro entorno se ha tendido a analizar otros grupos humanos en exclusión, como judíos y moriscos, pero de los gitanos poco se ha dicho. Es como si una alfombra historiográfica hubiese tapado la estela que ha ido dejando este pueblo a lo largo del tiempo, estudiándolo solo como parte de un colectivo antisocial a integrar en los comportamientos y pautas sociales imperantes y mayoritarias. Lamentablemente, este vacío o carencia de estudios más centrados en los gitanos no solo es una realidad que afecte a la investigación de los periodos referentes al Antiguo Régimen, donde la falta de documentación de esta etnia como protagonista escasea; al contrario, tampoco en la llamada Edad Contemporánea se ha abordado de manera amplia. Tanto es así que sucesos tan trágicos para el pueblo gitano en España como la Prisión General o Gran Redada de 1749, o en Europa como el Porrajmos, Samudaripen u holocausto gitano, apenas son mencionados en los libros de texto de nuestra educación obligatoria.

Estas familias que residían a ambos lados de la frontera de Espańa y Francia fueron desarrollando su asimilación o reafirmación cultural, siguiendo las diferentes políticas estatales. Se produjo un duro enfrentamiento entre la diferente concepción de la vida de las personas gitanas y sus vecinos vascos no gitanos. El grupo de gitanos vascos era idéntico durante el siglo XIX en todas las tierras vascas, y se diferenciaban de otros gitanos espańoles y franceses por la cultura que habían absorbido de sus vecinos y su asimilación al resto de la sociedad. En Francia ya en el siglo xx la administración no les considerará personas asociales como a otros nómadas; en España cuando lleguen los gitanos castellanos, estos verán a los gitanos vascos como payos. Para la sociedad mayoritaria todos serán gitanos, pero tendrán una consideración muy diferente. 
En este trabajo, por lo tanto, se investiga a un grupo humano concreto: el pueblo gitano vasco, tanto el que reside en la zona espańola como el que lo hace en la francesa, incidiendo, sobre todo, en el periodo comprendido por el siglo $\mathrm{XIX}^{1}$. En buena medida, las familias gitanas que desarrollan su vida en las actuales provincias vascas y Navarra lo hacían también en el momento que se sitúa el estudio en Francia, en el espacio que hoy en día se denomina Communauté d'agglomération du Pays Basque, dentro de la región francesa de Nueva Aquitania ${ }^{2}$. Tanto en el País Vasco francés como español, a este grupo de personas gitanas se les ha denominado históricamente ijitoak, asiaganbariak o motzaillak. Este último término hace referencia a su oficio de esquiladores de ganado ${ }^{3}$. Además, en la zona vascofrancesa se les conoce como buhameak o bohemiens. La necesidad de abordar a los gitanos en dicho ámbito geográfico viene dada por la constatación de elementos diferenciadores. Se ha de advertir que aunque se ha tendido a homogeneizar al pueblo gitano en los estudios historiográficos pretéritos, no ya solo a escala europea, sino también española, en realidad es muy heterogéneo ${ }^{4}$.

El marco geográfico que se aborda en las sucesivas líneas también está limitado a una cronología; en concreto, al siglo xIx. En primer lugar, esta centuria y la llegada de la industrialización supuso para el pueblo gitano, al igual que para muchas otras personas que no formaban parte de él y que vivían en el medio rural, el comienzo del gran cambio en su modo de vida. En segundo lugar, el ochocientos es la centuria que cuenta con las últimas disposiciones forales abiertamente antigitanas, aunque la Corte Real española ya se había pronunciado en sentido contrario en 1783 , en una pragmática que buscaba la integración jurídica de los gitanos. Las provincias vascas y Navarra, con prerrogativas propias y régimen foral, iban por su lado y se mantenían en una

1 El tema se haya prácticamente inédito tanto en el marco geográfico como en el periodo a tratar, aunque el panorama no resulta completamente estéril. Recientes estudios como los de las historiadoras Lougarot (2009) o Sutre (2010) en Francia, y los trabajos del propio autor de este artículo, Martín Sánchez (2016) y (2017), en Espańa son claros ejemplos de la recuperación de la historia del pueblo gitano vasco.

2 El País Vasco francés lo conforman los territorios históricos existentes antes de la división departamental de Francia en 1789. Estos son: Labourd, Basse-Navarre y Soule.

3 Gracia Cárcamo (1996): 532.

4 El debate sobre la idea de asimilación por parte de los Estados o comunidades políticas de los grupos de personas que las conforman es largo. Destaco a Goldberg (1994: 5), quien asegura que frente al discurso historiográfico de la monocultura se debería reconocer a la «heterogeneidad como la norma». 
postura de expulsión de los gitanos ajenos al sometimiento de la disciplina social. El arraigo del pueblo gitano era además rechazado, considerando a sus miembros como extranjeros, o al menos no vascos, bajo el argumento de que gracias a los Estatutos de Limpieza de Sangre y la Hidalguía Universal, el legislador jamás había permitido su asentamiento. Esta actitud por parte de las justicias vascas y navarras provocó que sobre el pueblo gitano pesase una doble imposición penal. Por lo tanto, un primer objetivo de este estudio es ayudar a completar la maltrecha historia del pueblo gitano, sobre todo en el ámbito espacial y temporal que se ha marcado.

La historia de un grupo humano, como dice Josep Fontana, es su memoria colectiva y cumple respecto de él la misma función que la memoria personal en un individuo: la de darle un sentido de identidad que lo hace ser él mismo y no otro 5 . Sin embargo, a la hora de conformar la historia del pueblo gitano pocas veces se ha recurrido a su memoria para contextualizar culturalmente su pasado, optando por tratar la información como si de un grupo étnico desaparecido se tratase. De este modo, se ha banalizado la nominación de condición de persona gitana, atribuyéndosela a individuos que cumplen con arquetipos fósiles y normalmente peyorativos. No se está hablando de realizar una construcción histórica de un pueblo para usarla con fines educativos y difusores en aras de creación de una conciencia colectiva, al estilo de los nuevos Estados nacionales del siglo XIX, tan solo de respetar unas premisas claras: integrar las máximas visiones posibles de su pasado.

En la metáfora del desfile en marcha que hace E. H. Carr sobre el curso histórico, el historiador, dice, es parte de la historia, y por lo tanto, su posición en el desfile determina su punto de vista sobre el pasado ${ }^{6}$. ¿Falta de objetivismo? La balanza de la historia del pueblo gitano se ha inclinado mucho tiempo de un lado, del de los "gitanólogos» positivistas, pero corre el riesgo de inclinarse totalmente al lado contrario, al de la militancia subjetivista y la redacción interesada del tema. No se pasa por el centro, por el equilibrio, en definitiva, por un multisubjetivismo que desemboque en una postura nivelada. Por lo tanto, el segundo objetivo que se ha marcado este artículo es el del estudio del pueblo gitano desde una óptica transversal, buscando una lectura de las fuentes primarias y documentos impresos lo más centrada posible, aunando discursos subjetivos de diferente índole. No solo se han usado textos procesales o disposiciones jurídicas, sino también manifestaciones populares, como registros literarios de diferente naturaleza, o mensajes del folclore.

Fontana (2001): 11.

6 Carr (1979): 47. 
Un tercer objetivo, y una de las originalidades de este artículo, es desmontar el mito del desarraigo del pueblo gitano en el País Vasco. Siendo considerados como extranjeros, como naturales de la tierra o incluso como originarios de Egipto, lo cierto es que el pueblo gitano llegó en el siglo XV a tierras vascas para no abandonarlas jamás. Su asimilación fue paulatina, pasando a formar parte de la sociedad que, mejor o peor, les había acogido. La gran diferencia con los gitanos asentados en otras zonas de la península ibérica fue que la cultura gitana en el mundo vasco se invisibilizó o se absorbió. Analizando en profundidad el folclore vasco se observa que la huella gitana está muy presente en representaciones carnavalescas, mascaradas o pastorales, pero está asumido como algo propio vasco, restando la importancia al legado gitano de dichas demostraciones. No sucede así en Andalucía, por ejemplo, donde lo gitano está muy relacionado no solo con las manifestaciones lúdicas, sino con su sociedad. En cualquier caso, es en el siglo XIX cuando el grupo de personas gitanas que habitaban las tierras vascas quedó definitivamente vinculado de manera sinalagmática con el resto del pueblo vasco. Durante ese siglo, se culminó la creación específica del grupo vasco de gitanos que pertenece al pueblo, el gitano, más transeuropeo que se conoce.

Desde la perspectiva metodológica, en este trabajo se ha seguido el método conocido como microhistoria. Es fundamental para la historia del pueblo gitano, llena de descripciones aisladas, ya que la microhistoria, como señala Levi, «intenta no rechazar todas las formas de abstracción, pues los hechos mínimos y los casos individuales pueden servir para revelar fenómenos más generales» ${ }^{7}$. Se reduce la escala de observación y a partir del interés por la cotidianidad de los individuos se ha construido una realidad que intenta aclarar las características del mundo que los rodea. La escuela italiana, con Ginzburg, Levi, Camporesi o Cipolla ${ }^{8}$, ha servido de instrumento referente a la hora de poder plantear un marco de estudio inicial, sin olvidar dirigir la mirada sobre aportes más recientes a esta corriente por historiadores españoles como Jaime Contreras o Tomás A. Mantecón?. Se sigue, además, una línea que puede considerarse como historia desde abajo, realizando un análisis crítico de las ideas explícitas que aparecen en las fuentes, aparte de utilizar materiales variados para conseguir información. Esta parte de la historia social enfoca a la gente ordinaria, entre la que se encuentran las personas gitanas. En

Levi (1993): 140

8 Obras referentes de estos autores de la escuela italiana de microhistoria: Ginzburg (2001); Levi (1990); Camporesi (1999), y Cipolla (1984).

9 Su obra se analiza en un artículo de Vincent (1999). 
este propósito de recuperar al individuo anónimo como sujeto histórico, más siendo un elemento marginal de la sociedad, encuentra sus exponentes en Eric J. Hobsbawm o Jim Sharpe ${ }^{10}$. Parafraseando a Ginzburg y sustituyendo la palabra "campesino" por la de "gitano», se puede observar que su teoría metodológica encaja perfectamente en el tratamiento de información que este estudio ha realizado: «Los historiadores no pueden entablar diálogo con los gitanos del siglo XVI. Por lo tanto, tienen que echar mano de fuentes escritas doblemente indirectas: en tanto que escritas y en tanto que escritas por individuos más o menos abiertamente con la cultura dominante. Esto significa que las ideas, creencias o esperanzas de los gitanos del pasado nos llegan a través de filtros intermedios y deformantes» ${ }^{11}$. En el caso del pueblo gitano, el caso parte con más desventaja aún si cabe, ya que el legado escrito tiene naturaleza jurídica y procesal.

Pero además de aprovechar los planteamientos de la microhistoria y de la historia desde abajo, y aunque parezca una contradicción, en este artículo no se desechan todas las formas de hacer historia. No es un enfrentamiento de escuelas, sino un plan de creación que se beneficia de los axiomas establecidos por los historiadores antiguos de diferentes tiempos. De este modo, el presente trabajo se detiene en sucesos políticos, como son las decisiones institucionales de represión plasmadas en disposiciones legislativas, para, a su vez, ver asuntos más cercanos que forman construcciones culturales. Es una narración de acontecimientos que los analiza estructuralmente. Se tiene la necesidad de estudiar la historia del pueblo gitano dentro de un marco objetivo, profundizando más allá de la epidermis de la documentación, creando hipótesis sin cargas sentimentales. Es decir, empirismo más historia cultural.

El artículo abordará, en primer lugar, la aparición del pueblo gitano en las tierras vascas. Las fechas coinciden con la cronología de su arribo al resto de Occidente, y muy brevemente se relatará la documentación de su llegada. Posteriormente, se presentará la relación de los gitanos con el resto de la sociedad vasca durante el siglo xix plasmada en los textos de la época, para continuar viendo las medidas represivas que adoptó la administración contra ellos. Finalmente, se afrontará el capítulo más interesante, el de comprobar cómo las políticas de control adoptadas por los Estados francés y español, junto con otra serie de factores de índole sociológica, provocaron el desigual desarrollo de lo que eran en un principio las mismas familias gitanas vascas.

10 González (2013) hace un repaso sobre la numerosísima obra del historiador británico Eric J. Hobsbawm; Sharpe (2009): 38-58.

11 Ginzburg (2001): 12. 


\section{PRIMERAS ETAPAS DE UNA HISTORIA: LA LLEGADA DEL PUEBLO GITANO A TIERRAS VASCAS}

Los primeros documentos que hacen referencia al pueblo gitano en las latitudes geográficas objeto del presente estudio son del siglo Xv. El 27 de abril de 1435 se emitió una donación hecha por la Corte de la reina Blanca de Navarra en el castillo de Olite a Tomás, conde de Egipto Menor, que, en compañía de un grupo de personas, solicitaron estancia en el reino de Navarra para después continuar su peregrinaje a Santiago de Compostela. Es un recibo en romance navarro descrito en la base de datos de la siguiente forma: «1435, abril 27. Olite. Tomás, conde de Egipto Menor, reconoce que ha recibido de Gil Pérez de Sarasa, tesorero del reino, 24 florines por cumplir un mandato de la reina Blanca. Romance navarro $»^{12}$. Este es el segundo texto que menciona a personas gitanas en la península ibérica, después de que ya lo hiciese otro, diez años antes, en la Corona de Aragón ${ }^{13}$. Posteriormente, en Álava existe un registro extenso, desde 1484 hasta 1552, de limosnas entregadas por las autoridades vitorianas a grupos de gitanos para que no entrasen en la ciudad, lo que prueba su presencia en dicha provincia por lo menos desde finales del siglo $\mathrm{Xv}^{14}$. El siguiente texto más antiguo que se ha encontrado se localiza en Guipúzcoa, y está fechado en $1510^{15}$. Se trata de una ejecutoria del pleito litigado por Inés de Osinaga, vecina de Ońate, con Juan Estíbaliz de Olalde, alcalde ordinario de la misma villa. En él, Inés de Osinaga acusaba a Juan Estíbaliz de Olalde por actuar parcialmente en un pleito criminal que ella había tenido contra María y Catalina, «dos egipcianas que le habían robado

12 AGN. Comptos. Cajón 138, n.o 4, 20. Recurriendo al propio documento, la justificación del pago consta del siguiente modo: «[...] por mi et mi compañía que ymos a conplir las penitencias que por el Padre Sancto nos a mandado [...]».

13 "[...] com l'amat e deuot nostre don Johan de Egipte Menor, de nostra licencia anant en diuerses parts, entena passar por algunes parts de nostres regnes e terres", recogido en el apéndice 1 de López De Meneses (1968): 251.

14 Bazán Díaz (1995): 180. Muestra un cuadro detallado donde se refleja la entrega de limosnas a los gitanos, para evitar que entraran en la ciudad, y evitar así presuntos desmanes, incluyendo la cantidad de dinero gastado en tales comisiones. Los años son: $1484,1488,1490,1491,1494,1495,1498,1499,1510,1511,1514,1515,1516$, $1517,1528,1532$ y 1552.

15 Esta fecha desmonta los estudios realizados hasta ahora con respecto a Guipúzcoa, que marcaban fechas muy posteriores de aparición [algo que cuestiona acertadamente Bazán Díaz (1995): 177-178]. Así, el clásico Gorosábel (1972: 324) localiza el primer documento de gitanos en Gipúzcoa en 1604. 
ropa y dinero de su casa ${ }^{16}$. No es un texto positivo, como tampoco lo serán los siguientes de Valmaseda en $1517^{17}$ o de Hernani en 1535, que aluden a la entrega de dinero por parte de las autoridades con la intención de alejar a los gitanos, ya sin cartas de protección, de sus jurisdicciones ${ }^{18}$ :

Los que de yuso firmamos nuestros nonbres, mandamos a vos, San Juan de Alçega, nuestro bolsero, que deys e pagueys a çiento e más egiçianos que benieron oy, dicho día, a esta villa, veynte chanfones. Los quales se los mandaron librar por mandas del conçejo, asy porque luego se fuesen de la dicha villa como por la costunbre que en ella se ha tenido de muchos años a esta parte en la dicha villa de dar a otros semejantes la cantydad susodicha ${ }^{19}$.

Era una práctica que venían haciendo en la villa «por la costumbre que en ella se ha tenido de muchos años a esta parte», lo que denota que los habitantes de Hernani preferían pagar todos los años una suma de dinero a los gitanos a dejarlos establecerse en sus términos. Solo un día y una noche podían tardar en cobrar su tributo ${ }^{20}$. Sin embargo, esos mismos años los escribanos de otras villas vascas también registraron en sus libros de cuentas los pagos que hicieron a los gitanos por bailar en sus fiestas patronales. Esta actitud denota una relación interesada por parte de los poderes locales con aquellos que no querían que residieran es su jurisdicción.

Los grupos de gitanos que se encontraban en las provincias vascas no diferían de los que andaban en Navarra, y que, según señala Idoate, a fines del XVI eran bastante numerosos en ese reino, procedentes en su mayor parte de Castilla, Aragón y Francia ${ }^{21}$. Efectivamente, cruzando apellidos se comprueba que muchos de los individuos que aparecían en el reino de Navarra lo hacían también en las provincias vascas.

ARChV. Reales Ejecutorias, 363-32.

17 De los Heros (2014): 406.

18 También se encuentra información similar en los libros de cuentas de Urretxu de 1540: AM Urretxu, 1er Libro de Cuentas, ff. 87r, 90r, 91r y 98r; o en los de Ordizia de 1541 (AM Ordizia. Libros de Repartimientos, Libro 2, f. 27r): «Yten, a veynte e dos de junio del dicho año [1541] que benían otros yjytanos y porque saliesen de la villa e su juridyçión por mandado del señor alcalde e les dí dos reales, los quoales se fueron». Agradecer a Iago Irijoa por la localización de muchas de estas fuentes pertenecientes a libros de cuentas.

19 AM Hernani, C-2-1-2; 3er cuadernillo, f. 14r.

20 Ibid., f. $15 \mathrm{v}$.

21 Idoate (1949): 450. 
Los gitanos de los siglos XVI-XVIII no se consideraban a ellos mismos como tales, es decir, no se llamaban a sí mismos gitanos porque no les favorecía. El ser gitano estaba tipificado en las normas jurídicas, existiendo pragmáticas, decretos y, en definitiva, un amplio cuerpo legislativo en su contra. Evidentemente, no fue exclusivo de los gitanos vascos; a nivel europeo el legislador promulgó gran cantidad de normas de control y castigo hacia el pueblo gitano. En España, entre 1499 y 1783, se emitieron más de 250 providencias formales dirigidas a su reducción social ${ }^{22}$. Con este paisaje legal, durante mucho tiempo no se reconocieron como de nación gitana, ni siquiera como pueblo común, sino como oriundos de la provincia de Guipúzcoa, del reino de Navarra o incluso del reino de Francia. La traducción de esta situación abstracta requiere para la investigación histórica el examen de los antepasados del que hoy se conoce como pueblo gitano vasco a través de sus hábitos, costumbres, genealogías y lengua. Fue el legislador el que marcó esta serie de rasgos distintivos y que, paradójicamente, ayudan en la actualidad a determinar quiénes eran considerados gitanos en los siglos pasados ${ }^{23}$.

La itinerancia y el trabajo ocasional no se admitían. En numerosas ocasiones, su existencia fue negada hasta por las propias justicias de la época, si bien en las instancias inferiores no eran de la misma opinión, reconociendo a personas gitanas entre la población de sus villas. Teóricamente no vivían gitanos y gitanas en las tierras forales, y así lo reflejaron los corregidores cuando fueron preguntados desde la Corte en 1749, en plena Gran Redada, por ejemplo. Nada más lejos de la realidad. Los alcaldes y otros cargos municipales sí conocían la condición y arraigo de los habitantes de su jurisdicción, así como la calificación que entre los vecinos tenían. Ellos fueron los que decidieron ejecutar o no las normas legales que tenían a su disposición. Llevar adelante una comisión de expulsión conllevaba gastos extras y las justicias locales no estaban por la labor de desembolsar de sus propios recursos los peculios necesarios que se requerían. Sumado a que el ser considerado gitano no tenía por qué significar un elemento de alteración en la convivencia con el resto de los vecinos, muchas personas gitanas siguieron viviendo en las provincias vascas sin ser molestadas por las justicias locales. De este modo, no coincide la voluntad del legislador con la de los aparatos ejecutivos municipales, por lo que el investigador no se puede despistar observando únicamente la documentación judicial y sí debe ampliar el estudio a las genealogías u otros instrumentos que muestren la existencia efectiva de personas prohibidas por la ley. Este contraste entre teoría jurídica y realidad social conforma una interesante

22 Gómez Alfaro (2010): 21.

23 Martín Sánchez (2017): 68. 
evolución. Recapitulando, varias circunstancias provocaron la singularidad del pueblo gitano vasco: el contacto con la cultura vasca y sus gentes, la situación fronteriza y la existencia de leyes forales que se solapaban con las supraprovinciales.

\section{LAS ACTITUDES DE LA SOCIEDAD VASCA ANTE LOS GITANOS DURANTE EL SIGLO XIX}

Existen numerosos textos del siglo xIx que dan información acerca del pueblo gitano desde una óptica de la sociedad mayoritaria de la época. En algunas ocasiones son pasajes de naturaleza judicial o discursos policiales; en otras, ensayos de intelectuales. Su contenido va más allá de las simples disposiciones legales o documentos procesales de los siglos anteriores y desarrollan con más detalle la visión que tenían los contemporáneos, de manera generalizada, sobre el pueblo gitano vasco. Una documentación que, como se podrá comprobar, se dio tanto en la parte francesa como espańola.

En 1857 se publicó una obra en francés sobre el País Vasco, cuyo séptimo capítulo está dedicado a los gitanos vascos ${ }^{24}$. Comienza diciendo que hay dos maneras de presentar su vida. La primera, fundamentada en la tradición y las conjeturas transmitidas de una generación a otra, con mensajes incoherentes, contradicciones y absurdos, y con contenido para una obra de ficción; la segunda consiste en representar a los gitanos tal y como los ve la gente de la zona, día a día. Normalmente, dice el autor, las personas que no tienen trato con los gitanos son las que más temor tienen, inventando leyendas sobre ellos. Sitúa el origen de estas personas gitanas en España, quienes, desde que sufren la dura persecución por parte de sus autoridades, a fines del siglo xv, deciden establecerse en los territorios históricos vascos del reino de Francia: Labourd, Soule y Basse-Navarre. Hace un repaso de todas las pragmáticas y disposiciones que se dan contra los gitanos a ambos lados del río Bidasoa, desembocando en la redada de 1802 que supuso la prisión simultánea de quinientas personas gitanas y que se comentará más adelante. Descritos como enemigos del trabajo reglado y de la sedentarización, destaca una excepción, la de los kaskarot ${ }^{25}$ de Ciboure y Saint-Jean-de-Luz, quienes sí se habrían asentado y

24 Francisque-Michel (1857). El título del capítulo en la versión original es «Les bohémiens du pays basque», pp. 128-146.

25 Como los kaskarot se conoce a un grupo humano localizado en el territorio histórico vasco-francés de Labort. Aunque lo conformaban agotes, moriscos y otros marginados del Antiguo Régimen, la presencia de gitanos era muy alta. En las partidas de 
empleado de manera estable. Los demás, con trabajos esporádicos de esquiladores o vendedores de cestas y sombreros de paja, compaginaban su vida con la mendicidad y el pequeńo hurto. Durante el invierno se refugiaban en viejas cabañas de pastores abandonadas o granjas aisladas, pero con el buen tiempo dormían al raso. Así mismo, el autor comenta la ligereza con que se producían los matrimonios y las separaciones, sin mediación eclesiástica ni autoridad civil presente, asegurando que si el hombre estaba preso, la mujer buscaba otro compañero, aunque tuviese hijos del primero. Respecto a la religión, indica que generalmente no tenían, viviendo una vida material y brutal, aunque muchos de ellos estaban bautizados. Asegura que había ya muchos gitanos domiciliados en las villas, aunque no pagaban ninguna retribución. Enviaban a sus hijos a la escuela, donde aprendían a leer y a escribir en francés, estudiaban el catecismo católico y hacían la primera comunión, abandonando luego para siempre la Iglesia. Después, algunos se asimilaban, y otros desaparecían por los bosques y caminos, aitzean yaiac, aitzerat nahi ${ }^{26}$. El autor finaliza el relato previendo un triste final para los gitanos, pues subraya que de la población gitana vasca en Francia pronto no quedarían sino solo recuerdos. Como se observa, el autor intenta presentar una historia cercana del pueblo gitano, evitando caer en los mitos de la época y centrándose en la cotidianidad, utilizando relatos próximos a la sociedad vascofrancesa. Sin embargo, desde esa pretendida familiaridad, no deja de existir cierta contradicción en su discurso, tratando, una vez más, a las personas gitanas con la ambigüedad que provoca el desconocimiento de su cultura, un claro síntoma de utilizar únicamente las fuentes orales de los vecinos payos sin preguntar a los propios gitanos.

El 3 de noviembre de 1863, se publicó un discurso pronunciado en el Tribunal Imperial de Pau, a cargo del fiscal general M. Lespinasse, titulado Les bohèmiens du Pays Basque ${ }^{27}$. Dibuja un panorama de personas miserables y sin inteligencia suficiente para revertir su situación. Apela a la caridad y a la búsqueda de una solución para poderlos ayudar a salir de la pobreza y la marginación, ante lo que considera unos prejuicios injustificados hacia los gitanos vascos. Recuerda que, tras la represión sufrida a principios del siglo, muchos habían escapado a Espańa o permanecían en Francia viviendo de las limosnas. Han aprovechado también, dice, las desgracias sociales que ha vivido el país durante la primera mitad de siglo para campar a sus anchas hurtando y

nacimiento y defunción se alternan las denominaciones de bohemien (gitano en francés) y cascarota (kaskarot en euskera) a las mismas personas.

26 Francisque-Michel (1857: 142) traduce esta frase originalmente vasca en francés: "Qui est né dans boi, aime à y revenir».

27 Lespinasse (1863). 
asaltando viajeros. Señala el fiscal que entre 1859 y 1860, 85 gitanos vascos fueron transferidos a los departamentos centrales de Francia, y entre 30 y 40 menores fueron recogidos por la beneficencia, realizando una vez más una dispersión familiar para intentar frenar la escalada de robos y agresiones que cometían a la población local. No surtió efecto, ni tampoco otras medidas adoptadas contra las personas gitanas en el pasado, por lo que el fiscal general propone como única solución moralizarlas e instruirlas: «De ces sauvages faire des hommes». Reconoce la habilidad de los hombres esquilando a los caballos, pero lamenta que lo hiciesen de manera aislada, buscando la mínima oportunidad para no trabajar y continuar con su vida ociosa. Finaliza señalando que no eran personas que poseyeran propiedades inmobiliarias, remarcando que no conocía a un solo gitano que hubiese transmitido en el distrito de Mauléon una casa a sus hijos.

En el xix, en Francia, se consolidaron con formas modernas prejuicios que ya venían de épocas anteriores, y otro ejemplo son los estudios realizados por Victor de Rochas. Este cirujano del ejército francés, viajero y con inquietudes antropológicas, escribió sobre todo acerca de las poblaciones caníbales de Nueva Caledonia, pero también se aproximó a lo que él denominó parias de Francia y Espańa. En 1876 dedicó un apartado a los gitanos vascos en una obra ya clásica entre los investigadores de historia social en el País Vasco ${ }^{28}$. Sobre sus contemporáneos gitanos dice que habían elegido ese lugar para vivir entre las montańas y las fronteras para evitar a las fuerzas armadas de ambos países. Tras el oficio de cesteros y chalanes se escondía también el arte de la fullería y el fraude, más que el atraco a mano armada. Sobre las mujeres apunta que, so color de vender cestas y esteras, sacaban dinero de leer la buenaventura. Pero destaca que aquí los gitanos habían encontrado su tierra prometida, donde los caballos y las mulas andaban libres por los bosques y los cerdos se alimentaban lejos de las granjas. La práctica habitual del abigeato estaba amparada por la frontera, vendiendo el caballo francés robado en España, y el español en Francia. Entre 1815 y 1825, escribe, hubo un recrudecimiento en la conducta de ciertos gitanos vascos, impulsada por un jefe de ladrones llamado Bidart, que "puede ser que no fuera de su raza». Otra banda de asaltantes que les siguió fue dirigida por un tal Ardaix, ese sí gitano, aunque enroló entre las filas de sus malhechores a todos los hombres facinerosos del lugar, «sin distinción de razas». Es un ejemplo de la asociación que se hace entre delincuencia y gitanos. En este caso, es muy posible que el elemento gitano fuera mínimo; sin embargo, de cara a la sociedad, la banda de forajidos proyecta la mala imagen y reputación que arrastra desde hace siglos. En 1829

28 Rochas (1876). 
la policía francesa puso fin a estos desmanes enviándolos a un presidio. Los ańos siguientes, la paz social entre los gitanos vascos y sus vecinos no se mantuvo, y fueron numerosas las voces que se alzaron para lograr su expulsión en masa, incluso hay quien, mediante artículos periodísticos, reclamó su aniquilación física: "Qu'abattre un bohémien d'un bon coup de carabine est chose aussi légitime que de tuer un loup ou un renard $»^{29}$.

En la línea de las descripciones pseudocientíficas que se van a extender a lo largo del siglo xix, el autor se atrevió a dar una representación física del gitano vasco: es de una talla por encima de la media, y se distingue del resto de la población por su tez, en mayor o menor medida, morena, su figura redondeada o ancha, que no es la de trazos finos de los vascos. Tienen los cabellos lisos, negros o castaños, grandes dientes, y los ojos vivos, con un color verdusco o azul claro, que sí comparten con sus vecinos. Este rasgo bien podía ser una señal de su mestizaje con el resto de la sociedad, y así lo remarca Rochas, quien aseguraba que los gitanos vascos tendían cada vez más a confundirse con el resto de la población y era difícil identificarlos por sus características físicas. A su juicio, dice, los gitanos vascos se acercaban cada vez más a las villas, donde se establecían como fabricantes de sandalias o como agricultores. En dichos lugares se comenzaron a formar parejas mixtas que provocaron el principio del fin del tipo gitano, diluyéndose en el resto de la sociedad. En la mezcla con los indígenas vascos, apunta, se podía reconocer el tipo gitano hasta la tercera generación. Todos hablaban euskera, aunque con un acento particular y apoyándose en gesticulaciones de manos y cabeza. Vestían igual que las demás personas de su entorno, aunque los niños y las mujeres iban algo más desaliñados. En un barrio representativo de Bussunarits, cerca de Saint-Jean-Pied-de-Port, de los quince hogares de gitanos que se contabilizaban, ocho eran mixtos, siendo el hombre no gitano lo que predominaba. El caso de sedentarización de los kaskarot, junto con lo antes señalado, le lleva a pensar que los gitanos se podían «civilizar»", siendo la mayor preocupación la de hacerles olvidar su origen.

Dentro de este escrito se debe destacar una idea que crea el habitual contrapunto de todo discurso complejo sobre el pueblo gitano entre las descripciones peyorativas y su defensa. En el siglo XIX surgen voces que oscilaban hacia un amparo de las personas gitanas. De este modo, Rochas destacaba las del Marqués de Nadaille, alto cargo militar del Departamento de los Bajos Pirineos (actuales Pirineos Atlánticos), y de M. Cerquand, miembro de la

29 «Dispararle a un gitano con un rifle es tan legítimo como matar un lobo o un zorro». Rochas (1876): 238.

30 Utiliza la siguiente expresión: «Ne sont donc pas incivilisables». Rochas (1876): 264. 
Sociedad de Ciencias de Pau ${ }^{31}$. Estas dos personalidades de la Administración y de la cultura vascofrancesa señalaban que no todo lo que se decía sobre los gitanos era verdad, y que más que lobos, eran corderos. Si bien, dicen, tenían como arma la makila, o bastón de hierro, como el resto de los vascos, era muy raro que la usaran, incidiendo que se podía encontrar algún asesino entre ellos, como también en el resto de la sociedad, pero que durante muchos años no habían cometido ningún crimen.

Otra interesante fuente de información, en este caso al otro lado de los Pirineos, la constituye la comprendida en la circular n. ${ }^{\circ} 2$ que hace referencia a la sesión que celebra la Diputación Provincial de Guipúzcoa en 1884. Este texto denota los graves conflictos existentes entre parte del pueblo gitano que no vivía asentado en un domicilio fijo y los habitantes de la región. Su tono es muy severo, quizá uno de los más duros que desde una institución vasca se haya podido hacer nunca contra las personas gitanas. La comisión encargada de formular el dictamen sobre la cuestión de los desmanes que ciertos gitanos estaban cometiendo en la provincia expresaba del siguiente modo su resolución a la Diputación:

[...] los que suscriben son los encargados de someter á su ilustrado criterio las medidas que conviene tomar para la tranquilidad de sus administrados y seguridad de sus vidas y haciendas, con ese grupo de vagamundos de profesión, conocidos con el nombre de gitanos, que tomando por pretexto los imperfectos rudimentos de determinado número de oficios, viven en realidad de la postulación, del merodeo y de la rapińa, imponiéndose en los campos y caseríos aislados por las amenazas y el terror que infunden sus hábitos y repulsivo aspecto.

Ingratos y pérfidos en todos sus actos, careciendo de toda clase de educación religiosa que pueda elevar su nivel moral é intelectual, permanecen estacionarios, vegetando en el último grado de abyección y embrutecimiento, empleando sus limitadas facultades y aptitud para todo lo que no tenga inclinación al bien, eludiendo la vigilancia de los agentes encargados de la conservación de la tranquilidad y el orden público ${ }^{32}$.

Se insistía, además, en que las autoridades habían sido demasiado tolerantes con estas personas hasta la fecha, y que sus bienhechores les compadecían y auxiliaban dejándose engañar y atemorizar. Recordaban que ninguna

31 Rochas (1876): 249.

32 Se puede consultar la copia original en varios archivos municipales de Guipúzcoa, como por ejemplo en: AM Hernani, E-2-II-5_1. 
nación había sabido poner remedio a sus desmanes, «rehusando comprender la utilidad y ventajas que el hombre reporta del amor al trabajo, y de los beneficios de la vida social». Esta actitud agresiva de los representantes guipuzcoanos con calificativos peyorativos e intenciones reductoras recuerda más bien a las posturas pretéritas de represión del siglo XviıI del resto de Espańa, y que parece no haberse superado en tierras vascas. En definitiva, este texto muestra la animadversión de las justicias guipuzcoanas hacia aquel sector del pueblo gitano vasco que no contribuía a las cargas provinciales y municipales. Quedaban exentas de tales calificaciones las personas gitanas domiciliadas y con trabajo reconocido, y cuyos hábitos y conducta moral no inspiraban temores ni recelos al vecindario. Familias que se fueron diluyendo poco a poco en el mapa humano de la comunidad, que recordarán solo en el futuro, y de manera anecdótica, su condición de gitanos.

Finalmente se debe mencionar a Ramón Soraluce, quien escribió el artículo «La vida de los gitanos en Guipúzcoa», en el que señala que estos habían constituido la excepción en virtud de su vida nómada:

El gitano en Guipúzcoa tiene su sello especial, un distintivo que le caracteriza y que va impreso á su modo y manera de ser: de tez morena, mirada penetrante y repulsiva, aspecto de virulentos, fumadores ellos y ellas, vestidos con pantalón de pana y blusa azul, con pańuelo amarillento y mantón las mujeres, provistas de su indispensable sortija y dóciles aparentemente, hablan el vascuence, pero con un tono y acento especial que desdice bastante el lenguaje común ${ }^{33}$.

El autor dice que poseían una organización interna y lazos de fraternidad con otras personas gitanas de las provincias limítrofes, señalando concretamente la de Vizcaya. Según apunta, y remitiéndose a las informaciones de los miqueletes, el cuerpo policial foral guipuzcoano, las cuadrillas de veinte personas se subdividían en otras de cuatro o cinco individuos, volviéndose a juntar al cabo de veinte días en las proximidades de alguna feria. Habla de un líder, conocido como Bonifacio, siendo sus sucesores Matías y Benigno ${ }^{34}$. En

\footnotetext{
Soraluce (1899): 177.

34 No se ha podido comprobar la existencia de todos estos líderes, ni tampoco contextualizarlos dentro de una rama familiar determinada, si bien pueden tener otros nombres en los registros. Cabe la posibilidad de que el Bonifacio al que se refiere el autor tenga por apellidos Echeverria Larralde, y sea un hombre bautizado en 1844 en Legorreta, y muerto en 1895 en San Sebastián, hijo de Miguel Echeverria Carriquiri y Juana Bautista Larralde Giménez. Sobre genealogías de gitanos vascos véase Martín Sánchez (2016).
} 
cualquier caso, el autor afirma que su procedencia originaria más inmediata había que situarla en el Pirineo francés "y de aquí su acento vasco-francés, característico en la mayoría de ellos».

Confirma las malas relaciones con los campesinos agricultores, quienes sufrían, según apunta, la rapiña de sus hortalizas y animales. Pero a la vez, los aldeanos se servían de sus servicios comprándoles cestos, que realizaban a las orillas de los ríos, o contratándolos para esquilar sus bestias. Y algo muy relevante es que Soraluce atribuía su vida errante y vagabunda a la "proscripción que ha pesado sobre su raza». Los miqueletes se encargaban de expulsarlos, aunque al poco tiempo regresaban a Guipúzcoa, se lamenta el autor, «y de todas las batidas la más memorable fue la realizada en connivencia con las provincias limítrofes, las que a su vez, con el auxilio de la guardia civil, les llevaron a las fronteras de Portugal, decayendo desde entonces bastante el número de los transeúntes en esta Provincia».

Alababa el autor la labor de la asistencia de los párrocos rurales intentando instruirles en la fe cristiana. Fruto de esa misión, apunta, fueron las inscripciones bautismales, aunque la cuestión de los matrimonios no se había subsanado. Aun así, estos registros no impedían que, llegado el momento de prestar los servicios militares, los jóvenes gitanos no se presentaran y fueran declarados prófugos.

Para finalizar, en la línea de los autores vistos anteriormente, vaticina la desaparición de las personas gitanas en Europa, "por lo que respecta a Guipúzcoa, este fenómeno se observa ya, existiendo determinadas familias aclimatadas y con carta de naturaleza en los respectivos pueblos, aunque en muy escaso número»" ${ }^{35}$.

Todos estos testimonios directos dejan una serie de lugares comunes, que se recuerdan una y otra vez, siendo el de las malas relaciones con la sociedad vasca uno de los más repetidos. Esta difícil convivencia derivó en la creación, por parte del legislador, de una serie de medidas para reprimir las conductas asociales y, en ocasiones, delictivas de las personas gitanas. Es algo que solicitaban los habitantes del lugar a sus mandatarios. Las disposiciones no se quedaron en el papel, y las administraciones se aseguraron de ejecutarlas. Los Estados liberales en desarrollo contaban con un engranaje burocrático lo suficientemente fuerte para poder controlar a su población. Ya no había resquicios de escape para las personas que estaban fuera del sistema y las medidas represivas fueron numerosas. Ello desembocó en un mestizaje cuasi forzoso e, irremediablemente, en la desaparición de la gitaneidad de estas personas, que se diluyeron en la sociedad aunque muchas continuasen situadas en la capa más baja de la misma.

35 Soraluce (1899): 178-179. 


\section{LAS MEDIDAS REPRESIVAS EN EL TRÁNSITO DEL ANTIGUO AL NUEVO RÉGIMEN}

A través de la permeabilidad del territorio vasco y de su tráfico comercial, las condiciones eran ideales para el contacto con el continente europeo y las ideas progresistas que traía consigo el siglo XIX. Sin embargo, las doctrinas ilustradas no impidieron el desarrollo de las imágenes heredadas de los siglos anteriores para con los gitanos. Seguían siendo acusados de realizar rapiñas, hurtos e incluso de ser ladrones de niños. El imaginario colectivo creó en la sociedad rural temor frente a los componentes del pueblo gitano. Para mitigar la situación se decidió renovar las armas legislativas existentes hasta el momento. Se desarrollaron las disposiciones contra los vagabundos, y se comenzó a fabricar en Francia la nueva legislación contra los nómadas, que se plasmó definitivamente en la ley de 16 de julio de 1912. Desde finales del siglo XIX se decidió expulsar a aquellas personas sin domicilio fijo que no tuvieran nacionalidad francesa, que no pudieran probar su arraigo. Los gitanos vascos no fueron comprendidos dentro de la mencionada disposición al considerarlos gente del país, y fueron los rom o gitanos del Este de Europa los mayores perjudicados. Pero mucho antes de llegar a este punto de control, la Administración francesa había llevado una operación de captura contra los gitanos vascos en 1802. Fue en la única región del Estado francés donde una maniobra de tal envergadura se llevó a cabo, y donde la población no se opuso, es más, participó en tal batida. Fueron civiles con cierto peso en los municipios los designados responsables para llevar a cabo la redada. La colaboración civil y militar fue esencial para su consecución ${ }^{36}$.

La conocida como rafle (redada en francés) de 1802 la ordenó el oficial Castellane, a la sazón prefecto en los distritos de Mauleon y Bayonne. Previamente, dirigió una carta al ministro de la Policía General pidiendo la captura total de los gitanos vascos y su posterior envío a las colonias de ultramar. De esta forma, pretendía erradicar lo que él veía como un mal permanente para su tierra, puesto que los consideraba criminales endémicos. Era una postura compartida por otros políticos del departamento como el senador Fargues, los consejeros del distrito y los comisarios de los tribunales de los distritos de Mauleon y Bayonne. Las autoridades francesas se pusieron en contacto con las españolas para establecer las directrices de un acuerdo bilateral y llevar así a buen fin la redada. El contacto español fue el marqués de las Amarillas, Juan

36 La información se encuentra de primera mano en: AGN, Procesos, VR_DOCUMENTOS, Leg. N. 15. Lougarot (2009) dedica un capítulo de su obra Bohémiens a esta redada. También se desarrolla en Martín Sánchez (2016): 434-446. 
Vataneo de la Cruz, cónsul en Bayonne, quien se encargó de contar al virrey de Navarra los planes de la administración francesa:

El comisario del Tribunal Criminal Especial de este departamento me ha escrito un oficio cuia copia incluía a V. M., e instándome a que escriba a V. E. para participarle que han dispuesto el Prefet y él hacer una especie de batida para prender a un sinfín de vagabundos de ambos sexos que se llaman gitanos o boemiens, que infestan todo el país de la Navarra La Baxa de Francia, y que para conseguir el fin que desean estas autoridades y el gobierno de esta Republica, necesitavan que V. E. se dignase poner un cordón de tropas en la frontera de la Navarra Alta, tanto para impedir que se introduzcan en Espańa semejantes jentes quanto para arrestarlos y entregarlos a las tropas de aquí, en caso de evadirse por esas fronteras ${ }^{37}$.

El virrey de Navarra informó al rey, quien se mostró de acuerdo y emitió una real orden para impedir que estos gitanos que estaban cometiendo «robos y delitos en el País Basco y la Baja Navarra [...] se refugiaran en España ${ }^{38}$. El virrey quedó satisfecho con esta colaboración entre ambas naciones. Estas familias solían pasar de Francia a España con asiduidad y la ayuda prestada había ayudado a establecer un control más férreo sobre las mismas.

Pero desde Francia no solo se pidió la ayuda a las justicias navarras, sino también a las guipuzcoanas. El cónsul escribió al comandante general de la provincia de Guipúzcoa, por petición del prefet francés, para que, por su parte, concurriese también a estas operaciones en toda la frontera de su mando y lograr así que no escapasen los gitanos por ningún punto ${ }^{39}$. Al parecer, algunos gitanos empezaban a notar la presión de las justicias francesas y habían comenzado a cruzar la frontera, deshaciendo un camino que sus antepasados de los siglos XVI y XVII habían hecho en sentido contrario.

La redada fue finalmente llevada a cabo la madrugada del 6 al 7 de diciembre de 1802, arrestando un total de 475 personas, 125 hombres, 155 mujeres y 195 menores de doce años ${ }^{40}$. Tras el éxito de la batida, los destacamentos españoles ya se pudieron retirar de los cordones. Las autoridades francesas les dieron las gracias por lo bien que habían cumplido en lo que a ellos les concernía respecto a la captura de esos casi quinientos gitanos bohemiens de las tierras vascas.

AGN, Procesos, VR_DOCUMENTOS, Leg. 68, N. 15, ff. 3r-v.

Ibid., f. 16r.

39 La petición, en AGN, Procesos. VR_DOCUMENTOS, Leg. 68, N. 15, f. 29r.

40 Lougarot (2009): 31. 
Este episodio infeliz de la historia del pueblo gitano vasco puede recordar a lo sucedido medio siglo antes en España, la conocida como Gran Redada de $1749^{41}$. Al igual que ocurrió en aquella ocasión, en esta batida de 1802 los gitanos encarcelados fueron luego puestos en libertad paulatinamente, desechando los proyectos de envío a las colonias de ultramar, de reclusión en centros vigilados, e incluso de colonización de nuevas tierras rurales ${ }^{42}$. Muchos de estos gitanos habían servido en el ejército francés, realizaban diversos oficios y, además, poseían pequeñas parcelas de tierra que cultivaban. La gran mayoría, tras ser liberados, volvieron a sus lugares de origen, tal y como lo certifican registros censales realizados en el siglo XIX, pero otros muchos, desposeídos de sus pertenencias y separados de sus familiares, se quedaron en tierras lejanas para ellos como Bourgogne o Auvergne. A los que permitieron volver a sus hogares se les vigiló a través de las autoridades locales. Fue un motivo más para intentar pasar desapercibido y quitarse el estigma de ser gitano en las sucesivas generaciones.

El juez de paz del cantón de Saint-Jean-de-Luz entrevistó tiempo después a Marie Ithurbide, de 88 ańos $^{43}$. Ella había sido una de las gitanas apresadas en 1802 cuando era joven, junto con su marido y su hijo de diecicocho meses. Cuenta que unos hombres llegaron a su casa y les detuvieron por orden del Gobierno, diciéndoles que les iban a enviar a un país extranjero donde les darían tierras y herramientas para trabajarlas. Los tres fueron conducidos al convento des Récollets, entre Ciboure y Saint-Jean-de-Luz, donde había ya familias gitanas presas y donde traerían aún más. Dos días después fueron conducidos a Bayonne, donde los hombres fueron encerrados en una pequeña prisión en Mignon y a las mujeres, niños y ancianos, en el convento des Capucins. Después de seis meses y medio, Marie Ithurbide fue enviada, junto con otras gitanas, a La Rochelle, y allí pasó dos años recluida antes de ser puesta en libertad, mientras que a su marido lo enrolaron en el ejército.

Pasado ese trágico episodio de la historia de Francia, el control de los gitanos continuó, aunque ya no se ejecutaron operaciones de tal envergadura. A finales del siglo xix con la modernización de las identificaciones se podía saber exactamente la población de gitanos. En 1860 el prefet de Basses Pyrenees solicitó saber el número exacto de gitanos que residían en el País Vasco

41 Sobre la denominada Gran Redada, ver Gómez Alfaro (1992); Martínez Martínez (2014), y Gómez Urdáńez (2004).

42 Uno de los proyectos, según consta, fue el de enviarlos a Louisiana, pero en abril de 1803 este territorio pasaría a ser de EE.UU. y desaparece dicha posibilidad.

43 Archives Municipales de Saint-Jean-de-Luz, FF 12, citado por Lafourcade (1989): 498. 
francés, todos ellos en su mayoría ya con arraigo demostrable. En 1873 en el arrondiment de Mauleón se identificaron 403 bohemios, 113 en el cantón de Saint-Palais, 57 en Saint-Jean-Pied-de-Port, 197 en d'Ijoldy, 11 en Mauleón, 35 en Naïgorry y 3 en Tardets. Todo ello se hace sobre una población de 62309 habitantes, lo que equivalía al 0,65\% de la población total. En 1876 eran 48 familias en Saint-Jean-de-Luz y Ciboure sobre 569 personas. Estas cifras no denotan una gran presencia de gitanos vascos en la sociedad vascofrancesa, pero su legado será muy evidente. Esta herencia se refleja principalmente en el folclore de la tierra con las mascaradas y pastorales como representaciones fundamentales del mismo donde el tema gitano es muy habitual, incluyendo no solo personajes de este pueblo, sino también tramas donde los protagonistas son los gitanos ${ }^{44}$.

En Álava, Guipúzcoa, Vizcaya y Navarra no se procedió de manera tan directa contra las personas consideradas gitanas, pero la convivencia tampoco fue fácil. Los encuentros entre los gitanos que cometían robos y los campesinos se tradujeron en finales trágicos con agresiones recíprocas. Fueron numerosas las personas gitanas denunciadas por practicar el pequeño hurto de, entre otras cosas, habas, maíz, gallinas, corderos y otras sustracciones menores que servían de complemento a su manutención. Es complicado analizar dichos actos desde una perspectiva moral general, sin comprender que esas rapacerías obedecen a episodios de supervivencia y no a robos con intención acumulativa o especulativa. Sin embargo, estas fechorías crearon recelos entre la gente de campo que, ante la llegada de grupos de gitanos a sus villas o tierras, ponían en cautela sus pertenecías. Cosa bien distinta, incluso a ojos de los propios perjudicados, era cuando se producía el robo de ganado mayor como caballos, yeguas, burros o mulas. Ahí, las justicias actuaban de manera directa, sin contemplaciones. La documentación penal sobre este tema no es residual y son numerosas las personas gitanas apresadas por este motivo. Junto con los pequeños hurtos, estos robos comenzaron a generar un malestar general entre el resto de población vasca que arrastró a las administraciones provinciales y locales a tomar medidas. Ello desembocó en una serie de disposiciones forales contra gitanos y vagabundos durante los sucesivos años.

En Guipúzcoa el asunto llegó a las Juntas Generales de julio de 1865, y a petición de la villa de Ataun se decidió crear un censo de las personas

44 Como ejemplos sirven los personajes llamados kauterak y buhame jaun en las mascaradas del territorio histórico del Soule, o los caldereros en Guipúzcoa. En las pastorales vascofrancesas la temática gitana es muy habitual. Recientemente Mixel Etxekopare ha escrito Ederlezi, que narra el devenir histórico de los gitanos vascos desde el siglo XviI hasta el Xxi. 
gitanas que habitaban la provincia «demostrando la urgente necesidad de que se pusiese coto á las demasías de los gitanos que vagaban por la Provincia» ${ }^{45}$. No parece que hubiese respuesta afirmativa por parte de ninguna villa, por lo que se puede establecer la hipótesis de que aquellos que protagonizaron los desmanes no estaban avecindados en Guipúzcoa, sino en lugares colindantes como Francia o la vecina Navarra ${ }^{46}$. «En esta villa no hay gitano alguno avecindado, ni se ha expedido cédula de vecindad a persona alguna de su raza», se responde desde la villa de Elgeta, a modo de ejemplo ${ }^{47}$. Sí contestó afirmativamente la villa de Andoain en diciembre del mismo año, cuando, en una reunión extraordinaria, se volvió a recordar a los alcaldes que enviasen «una relación nominal exacta de los gitanos que se hallasen avecindados en sus respectivas jurisdicciones $»^{48}$. En esta ocasión, lo que se ordenó fue comprobar las cédulas de vecindad de aquellas personas consideradas gitanas, vigilarlas, y si no justificaban hallarse domiciliados debidamente en Guipúzcoa, o si no demostraban trabajo fijo, se les debían aplicar las penas que para la vagancia establecía el código criminal. Además, se puso en sobre aviso al comandante del cuerpo de miqueletes, "con el fin de que se repriman, en lo posible, los abusos que cometen los gitanos y postulantes ${ }^{49}$. Los miqueletes ya venían haciendo expulsiones de postulantes, pero entre enero y julio de 1866 parece que la presencia de gitanos entre los mismos fue mayor. De este modo, y aunque no lo señalen directamente, expulsaron de Guipúzcoa a Navarra a personas con apellidos inconfundibles dentro del pueblo gitano vasco como Echeverria, Larralde, Berrio o Jiménez ${ }^{50}$. Expulsiones producidas, no hay que olvidar, cuando ya en el resto de Espańa no se llevaban a cabo.

En la sesión provincial que celebró la Diputación de Guipúzcoa en noviembre de 1884 , texto que ya se ha mostrado anteriormente, se incidió en fijar a las personas gitanas a una residencia, no ya expulsarlas, sino a emplearlas en obras públicas y mejorar su conducta moral y hábitos. Si todo ello no daba

45 El fragmento de texto pertenece a la circular n. ${ }^{\circ}$, fechada el 12 de julio de 1865 y emitida en Tolosa.

46 Se han consultado todos los archivos municipales de Guipúzcoa, y en ninguno se ha podido localizar una copia de la carta con la relación de las personas gitanas avecindadas. Tampoco en el Archivo General de Guipúzcoa.

47 AM Elgeta, A-12-7-1865.

48 AM Andoain, comunicación n.o 284, del 29/12/1865. Desafortunadamente no hemos podido localizar esa "relación nominal de los gitanos que se hallan avecindados en esta jurisdicción".

49 AGG-GAO, JD IT 2381, 12, sf.

50 AGG-GAO, JD IT 2382, 1-7. 
resultado, sí debían tomar otras decisiones más graves. El acuerdo no obtuvo el resultado deseado, y las quejas de los alcaldes continuaron. En 1890 se dirigió un oficio a la Diputación Provincial de Guipúzcoa por los alcaldes de Vergara, Elgoibar, Motrico, Éibar, Placencia y Deba, solicitando la toma de medidas contra los gitanos, pues se decía que extorsionaban a los habitantes de los caseríos, e incluso, añadían, se permitía hostigar a los jueces municipales, cuyas correcciones y castigos se mostraban insuficientes ${ }^{51}$. En el siglo siguiente no se abandonará la cuestión. Así, en 1931 se compendió un texto para que los miqueletes pudieran actuar contra las personas consideradas gitanas sin oficio ni residencia, en la línea de los reglamentos internos de la Guardia Civil y la posterior reglamentación estatal de la Ley de Vagos y Maleantes de 1933.

\section{MISMAS FAMILIAS, DISTINTOS CAMINOS}

Las líneas precedentes han mostrado la actitud y las medidas adoptadas por parte de las autoridades frente a la cuestión del pueblo gitano. Ante esta realidad, hay que plantearse cuáles fueron las consecuencias, mecanismos y respuestas planteadas por los propios gitanos. De hecho, aunque este artículo se centre en un ámbito cultural concreto, el vasco, se trata de un espacio partido en dos Estados y en diferentes provincias, por lo que es lógico pensar que las actitudes tomadas por sus respectivas instituciones dieron lugar a diversas reacciones entre los gitanos. En este sentido, una serie de factores políticos y sociales provocaron dinámicas evolutivas diferentes de las mismas familias gitanas vascas, dependiendo de su residencia francesa o española. Por un lado, si bien durante los siglos anteriores, en el reino de Francia la presión contra los gitanos no había sido tan sofocante como en las provincias vascas peninsulares y el reino de Navarra, la situación cambió a partir del siglo xix; prueba de ello fue la mencionada raffle de 1802. Además, eran tres grupos los que formaban durante este siglo el pueblo gitano en tierras galas. El primero lo constituían los gitanos vascos, los bohémiens, que crearon una serie de familias con clara vocación sedentaria y cuyos componentes tenían no solo los apellidos, sino los rasgos culturales de las gentes del país. El segundo era el de los manouches, que procedentes de Alemania, Bélgica o de países colindantes al este de Francia continuaron realizando una vida nómada con desplazamientos a lo largo de todo el Estado, manteniendo distancia con la sociedad que los rodeaba ${ }^{52}$. El tercer grupo, los rom,

51 AMEibar. E102.11. E- 10- Caja 2.

52 Los manouches se instalarán definitivamente en tierras vascas, así como en el Bearn, después de la Segunda Guerra Mundial. Para más información, véase Sutre (2010). 
era el constituido por las personas gitanas cuyo origen reciente se situaba en los Balcanes y otros lugares del este de Europa. Su vida estaba muy ligada al mundo del espectáculo y a oficios tradicionales de las tierras de donde procedían, como el trabajo del metal. Tanto estos últimos como los manouches, por su forma de vida, fueron el objetivo principal de las leyes para controlar a la gente nómada que promulgó Francia a comienzo del siglo xx.

Esta nueva composición del pueblo gitano provocó que los que estaban arraigados al País Vasco francés fueran distanciándose de su condición, intentando evitar así el estigma que la misma contenía. Simultáneamente, el trabajo en la agricultura y, sobre todo, la confusión con el resto del proletariado, más los matrimonios mixtos, fueron hechos que llevaron a partir del siglo XIX a ir diluyendo el componente cultural gitano dentro de la masa social vasca. Aquellas personas del pueblo gitano que mantuvieron sus tradiciones lo hicieron de una manera menos visible y de puertas hacia dentro. Se vieron empujados, la mayor parte de las veces, por el recelo de aquellos con los que convivían y no eran gitanos, y perdieron así su identidad. Esta frustración de la transmisión cultural provocó ya en el siglo xx el desconocimiento del origen por parte de muchos descendientes de gitanos ${ }^{53}$.

Al sur de los Pirineos, durante el siglo xIx, aunque existían leyes en contra del pueblo gitano, la ejecución de las mismas por parte de la justicia no fue $\tan$ fuerte. Tampoco existió una presencia de otros grupos de gitanos que avivase su estigma social ante el resto de la sociedad, más allá del arribo esporádico de los castellanos y las puntuales incursiones de los llamados húngaros-caldereros. El escritor Gregorio de Múgica, estando en Leiza, municipio navarro al norte de Pamplona, señalaba que un niño gitano que llegó a su casa pidiendo limosna respondió en euskera a las siguientes preguntas del investigador: primeramente si conocía el habla que utilizan los gitanos entre ellos, y el niño contestó afirmativamente. Múgica pasó a preguntarle si servía también para los gitanos castellanos, y el niño le contestó: «No lo sé, yo no conozco ningún gitano castellano» ${ }^{54}$. Este episodio sucedió en las primeras décadas del siglo $\mathrm{xx}$, cuando todavía los gitanos castellanos no se relacionaban con los gitanos vascos y las influencias lingüísticas no habían tenido lugar.

También, como en Francia, se produjo una asimilación natural en la sociedad, hasta el punto de desaparecer la cultura gitana de las personas cuyos antepasados sí la habían mantenido desde hacía tres siglos, por lo menos. Esto

53 En la tesis de Martín Sánchez (2016: 457-488), en el apartado de las genealogías, se desarrolla el tema de la disolución en la sociedad mayoritaria de ciertas familias gitanas.

54 Mújica (1921). 
sucedió, sobre todo, en los municipios pequeños y rurales. No obstante, sobrevivieron algunas familias que continuaron claramente con su identidad gitana y cuyos apellidos aparecen, de manera desigual pero constante, en la documentación procesal y en los registros parroquiales de la época, convirtiéndose en las mismas genealogías que conforman el pueblo gitano vasco en la actualidad: Abadiano, Altimasveres, Alunda, Berrio, Carriquiri, Echepare, Echeverria, Elizalde, Jiménez, Larralde, Minaverria, Urrutia o Valdés. Estas familias, lejos de renunciar a su condición de gitanos, fueron afianzando su orgullo identitario. Pese a que mantuvieron relación con gitanos de Aragón y Castilla, su endogamia ha durado hasta el siglo $\mathrm{xx}$, momento en el que se produjeron las grandes migraciones de carácter intraestatal que también afectaron al mundo gitano ${ }^{55}$.

En cuanto al asentamiento, desbaratando esa idea que se suele tener de las familias gitanas viviendo en las ciudades o sus alrededores, en el País Vasco eligieron zonas rurales para vivir. En Álava, Vizcaya y Guipúzcoa eligieron pequeñas villas como las de Aramaio, Orduña, Amezketa, Itsasondo, Orio, Lanestosa o Abadińo. En Francia optaron por lugares clásicos de establecimiento como Ciboure o Saint-Jean-de-Luz, así como enclaves agrarios: Hazparne, Ahetze o Ezpeleta. En Navarra las personas gitanas que tenían allegados al otro lado de los Pirineos se instalaron en el norte, pero la presencia del pueblo gitano en La Ribera fue también muy numerosa, un lugar que no han abandonado jamás: Falces, Funes, Fitero, Marcilla o Peralta. Si optaban por residir en las ciudades, lo hacían en zonas apartadas, como el barrio de Errotxapea en Pamplona, único suburbio que surgió en los extramuros de la ciudad, donde solo se podían construir por ley edificios de poca altura con materiales poco resistentes, y donde hoy en día todavía reside gran número de gitanos. Asentarse dentro de una ciudad y no diluirse entre la población manteniendo su condición gitana visible no era seguro y cualquier excusa era buena para expulsarlos. Como ejemplo, la ciudad de Irún, donde en 1836, en plena guerra carlista, las tropas tradicionalistas decidieron desterrar a todos los gitanos y vagabundos de la ciudad.

La lengua que utilizaban los gitanos durante el siglo xix era la misma que la de sus vecinos, el euskera, cuyo uso fue decayendo a lo largo del siguiente siglo, cuando se produce la mezcla con los gitanos castellanos y los asentamientos en las grandes urbes. En ese momento adoptaron el castellano como lengua vehicular, manteniendo parte del caló, vestigio híbrido del antiguo lenguaje gitano. En Francia los gitanos vascos hablaban euskera, y la mayor parte de las mujeres no sabían otro idioma. Los hombres de edad madura fueron los que aprendieron el francés en la escuela del ejército o en la prisión. Durante el siglo

55 Martín Sánchez (2017): 157-164. 
XIX se hizo un esfuerzo para que todos los niños fueran al colegio y allí aprendieran el idioma francés. El romaní lo tenían tan olvidado que apenas recordaban algunas palabras que entremezclaban con palabras vascas, y vocabulario carcelario $^{56}$. Un tema lingüístico interesante que se lleva trabajando desde hace tiempo, aunque sin resultados demasiado satisfactorios hasta la fecha, es el del vasco-romaní. Una serie de investigaciones del siglo xIx indicaban la existencia de una lengua vasca con unidades léxicas del romaní sin gramática estructurada, utilizado por las personas gitanas vascas. Más recientemente, a fines del siglo pasado, se retomó el tema, abordándose el estudio del vasco-romaní o erromintxela en un trabajo dirigido por la filóloga Josune Muñoz ${ }^{57}$.

Por otro lado, la música, como en otras regiones de la geografía peninsular, fue una escapatoria del estigma social para los gitanos, al menos de forma efímera. El oficio de tamborilero fue ejercido por gitanos y agotes durante varios siglos de manera ininterrumpida ${ }^{58}$, generación tras generación, y fue una labor reconocida por el resto de la sociedad ${ }^{59}$. El músico era bien recibido siempre, pero pasados los festejos, el recelo hacia esa misma persona que tocaba el txistu volvía a salir a la luz, solo redimiendo en parte la condición de su otredad. La música era un trabajo que se podía compaginar con otras labores, al igual que el esquileo. Eran oficios temporales, pero en este caso, no tenían impedimentos legales, todo lo contrario, eran aclamados y su contratación se realizaba conforme a disposiciones reguladas municipalmente ${ }^{60}$.

La transmisión cultural recíproca entre los vascos, gitanos y no gitanos se pone de manifiesto con lo que se ha señalado en este trabajo, como también la mezcla de las familias. Es poco probable que existiera una lucha consciente interna dentro del pueblo gitano vasco entre la asimilación y el reconocimiento de su cultura, al menos no entendida del modo en que lo hacemos en el presente. Sí es más sensato interpretar la disolución del pueblo gitano entre la población que le rodea como un modo de supervivencia y de mejora de condición social y de su vida diaria. Aquellos que no lo hicieron permanecieron al

56 Rochas (1876): 253

57 Muñoz, López De Mungía y Vizárraga (1996).

58 Para ver un estudio comparativo entre agotes y gitanos: Martín Sánchez (2016): 314320. Para profundizar sobre agotes: Aguirre Delclaux (1978) y Antolini (1986).

59 Un ejemplo paradigmático es el de Javier Echeverria, gitano nacido en el norte de Navarra, quien fue "chunchunero» de las fiestas de San Fermín en Pamplona, precediendo con su txistu y su tambor a los gigantes de la comparsa festiva desde mediado del siglo XIX hasta principios del xx.

60 Sobre txistularis y músicos gitanos vascos: Perurena (2016) y transversalmente Mendizabal (2017). 
margen, entrando en esa peligrosa amalgama de personas que se encontraban rechazadas socialmente o, como se dice en la actualidad, en riesgo de exclusión ${ }^{61}$. Las medidas adoptadas en el Estado francés contra el pueblo gitano y contra aquellas personas que no se establecían de manera fija en los municipios del país, sobre todo a partir del siglo XIX, aceleraron la invisibilidad de los gitanos vascos de estas latitudes. No queriéndose ver identificados con aquellas nuevas familias llegadas del Este de Europa, controladas férreamente por la Administración gala, el pueblo gitano del País Vasco francés optó por pasar desapercibido en cuanto a no mostrar rasgos diferenciadores. En cambio, aquellas familias, las que vivían en el País Vasco peninsular, y que entraron en contacto con los gitanos venidos de la meseta espańola y del sur, los castellanos, fueron las que principalmente recuperaron de alguna forma su sentimiento y orgullo de ser gitano. Resistieron con su diferencia ante la homogeneización de la sociedad, aunque en ocasiones el precio que pagaron fue muy alto, sufriendo en sus carnes de manera directa una discriminación que perdura hasta la actualidad.

\section{CONCLUSIONES}

Este estudio pone en evidencia la presencia de personas consideradas gitanas en tierras vascas durante el siglo XIX, donde se habían instalado desde el siglo XV a pesar de las prohibiciones implícitas en la jurisdicción foral. Ciertamente las leyes forales no permitieron durante mucho tiempo su establecimiento, y cuando lo hicieron fue solo bajo la condición de un domicilio estable, trabajo reconocido y abandono de sus rasgos culturales distintivos: lengua, traje y oficio.

Se produjo una formación específica de este grupo gitano a través de la relación con sus familiares residentes en Francia, donde su proceso de sedentarización e integración se aceleró en el siglo xix. Miembros de las mismas familias continuaron teniendo lazos de unión; sin embargo, los ritmos de asimilación a la sociedad fueron diferentes. Aquellas personas que quedaron residiendo en Espańa resistieron a la aculturación durante más tiempo, conservando su identidad gitana en los siglos posteriores, mientras que los que permanecieron en Francia se diluyeron en la sociedad.

El pueblo gitano quedó absorbido en muchos casos dentro de la sociedad mayoritaria de la época, para ir borrando las seńas identitarias que le

${ }^{61}$ Sobre desarraigo del pueblo gitano, consúltense los siguientes trabajos: https://bit. ly/2wcz0DA; https://bit.ly/2PtmYOT. 
provocaban un estigma social e incluso la expulsión. A sensu contrario, personas que étnicamente no procedían del propio pueblo gitano fueron señaladas como gitanas y pasaron a formar parte de él. La doble imposición penal, la mezcla, los préstamos culturales y el desenvolvimiento en el medio donde habitaban fueron los ingredientes que permitieron la creación del grupo de gitanos vascos en la actualidad.

La realidad es tan propia, marcada o diferente con respecto de otras comunidades que hoy en día existe un nutrido grupo de personas conocidas como "gitanos vascos", a quienes los propios gitanos venidos de la ribera navarra o Castilla niegan su condición como tal, denominándolos mercheros, quinquilleros o directamente payos. Sus antepasados fueron, en su mayoría, estos mismos gitanos y gitanas que se han estudiado en la presente investigación. Cruel paradoja la que establece una asignación de condición gitana, normalmente con carga negativa, a un grupo humano por parte de la sociedad mayoritaria, pero a la vez se le niega por el resto de personas gitanas.

Llegados a este punto, la investigación histórica desemboca en conclusiones que abren el debate a diferentes disciplinas como la antropología o la sociología, y por lo tanto es momento de finalizarlo, no sin antes remarcar que este trabajo es una muestra más de la heterogénea realidad que tan monolíticamente se ha solido plantear en la historia del pueblo gitano.

\section{Bibliografía}

Aguirre Delclaux, M. C. (1978). Los agotes. Pamplona: Institución Príncipe de Viana.

Antolini, P. (1986). Los agotes: historia de una exclusión. Madrid: Istmo.

Bazán Díaz, I. (1995). Delincuencia y criminalidad en el País Vasco en la transición de la Edad Media a la Moderna. Vitoria: Departamento de Interior.

Camporesi, P. (1999). El pan salvaje. Buenos Aires: FCE.

Carr, E. H. (1979). ¿Qué es la Historia? Barcelona: Seix Barral.

Cipolla, C. (1984). ¿Quién rompió las rejas de Monte Lupo? Buenos Aires: Muchnik Editores.

De Los Heros, M. (2014). Historia de Valmaseda: Villa del antiguo condado y señorio de Vizcaya. Valladolid: Maxtor.

Fontana, J. (2001). La historia de los hombres. Barcelona: Crítica.

Francisque-Michel (1857). Le Pays Basque, sa population, sa langue, ses meurs, sa littérature et sa musique. Paris: Firmin Didot frères.

Ginzburg, C. (2001). El queso y los gusanos. El cosmos según un molinero del siglo XVI. Barcelona: Península.

Goldberg, D. T. (1994). Introduction: Multicultural Conditions. En D. T. Goldberg (ed.). Multiculturalism: A Critical Reader (pp. 1-41). Cambridge, Mass.: Blackwell Publishers.

Gómez Alfaro, A. (1992). El expediente general de gitanos. Madrid: Universidad Complutense.

- (2010). Escritos sobre gitanos. Barcelona: Asociación de Enseńantes con gitanos. 
Gómez Urdáńez, J. L. (2004). La Real Casa de la Misericordia, cárcel de gitanas (1752-1763). En M. García Hernández y Ma. Á. Sobaler Seco (coords.). Homenaje a Teófanes Egido. Vol. I, (pp. 329-343). Valladolid: Junta de Castilla y León.

González, R. M. (2013) Eric J. Hobsbawm, la Historia desde abajo y el análisis de los agentes históricos. Rúbrica Contemporánea, 4 (2), 5-22.

Gorosábel, P. (1972). Noticias de las cosas memorables de Guipúzcoa. Vol. 1. Bilbao: La Gran Enciclopedia Vasca.

Gracia Cárcamo, J. A. (1996). La otra sociedad: los marginados. Revista Internacional de Estudios Vascos, 41 (2), 529-540.

Idoate Iragui, F. (1949). Los gitanos en Navarra. Príncipe de Viana, año 10, (37), 443-474.

Lafourcade, M. (1989). Mariages dans le Labourd sous l'Ancien Régime: les contrats de mariage du Pays de Labourd sous le règne de Louis XVI: (étude juridique et sociologique). Bilbao: Universidad del País Vasco.

Lespinasse, M. (1863). Discours prononcé à l'audience solennelle de rentrée à la Cour de Pau. Pau: Vignancourt.

Levi, G. (1990) La herencia inmaterial. La historia de un exorcista piamontés del siglo XVIII. Madrid: Nerea.

- (1993). Sobre microhistoria. En P. Burke (comp.). Formas de hacer Historia (pp. 119143). Madrid: Alianza Editorial.

López De Meneses, A. (1968). La inmigración gitana en España durante el siglo xv. Martínez Ferrando, miscelánea de Estudios dedicados a su memoria. Barcelona: Anaba.

Lougarot, N. (2009). Bohemiens. Larresoro: Gatuzain.

Martín Sánchez, D. (2016). El pueblo gitano en el País Vasco y Navarra (1435-1802) [tesis doctoral inédita]. Universidad del País Vasco-Euskal Herriko Unibertsitatea.

- (2017). El pueblo gitano en Euskal Herria. Tafalla: Txalaparta.

Martínez Martínez, M. (2014). Los gitanos y las gitanas de España a mediados del siglo XVIII. El fracaso de un proyecto de "exterminio» (1748-1765). Almería: Universidad de Almería.

Mendizabal, A. (2017). Hau leku aittorra! Oiartzun: Ayuntamiento de Oiartzun.

Mújica, G. (1921). El euskera de los gitanos. Euskadi, 131-132.

Muñoz, J., López de Mungía, E., y Vizárraga, O. Investigación socio-lingüística del Erromintxela. Bilbao: KDK.

Perurena, P. (2016). Goizuetako danbolintero batzuk (1608-1729). Cuadernos de Etnología y Etnografía de Navarra, 90, 209-236.

Rochas, V. de (1876). Les Parias de France et d'Espagne: (cagots et bohémiens). Paris: Hachette.

Sharpe, J. (2009). Historia desde abajo. En P. Burke (ed.). Formas de hacer historia. (pp. 38-58). Madrid: Alianza Editorial.

Soraluce, R. (1899). La vida de los gitanos en Guipúzcoa. Euskal-Erria. Revista vascongada, 41, 175-179.

Sutre, A. (2010). Les Bohémiens du pays. Une étude des modalités de l'inscription territoriale des Bohémiens dans le Sud-ouest de la France au XIXème et au début du XXème siècle [memoria de máster]. École des Haute Études en Sciences Sociales.

Vincent, B. (1999). Microhistoria a la española. Prohistoria: historia, politicas de la historia, 3, 231-236. 